\title{
Fever, CTCAE
}

National Cancer Institute

\section{Source}

National Cancer Institute. Fever, CT CAE. NCI Thesaurus. Code C143485.

A disorder characterized by elevation of the body's temperature above the upper limit of normal. 